\title{
A comparative study and experimental validation on single phase series active power filter control strategies using PI, FLC and sliding mode controllers
}

\author{
Abdallah Ben Abdelkader, Othmane Abdelkhalek, Ismail Khalil Bousserhane, \\ Mohamed Amine Hartani, Aymen Omari \\ Faculty of Technology, University of Tahri Mohammed Bechar, Algeria
}

\begin{tabular}{l}
\hline \hline Article Info \\
\hline Article history: \\
Received Sep 23, 2018 \\
Revised Nov 19, 2018 \\
Accepted Jan 26, 2019 \\
\hline Keywords: \\
Series active power filter apfs \\
Proportional integrator PI \\
Sag-swell, harmonics voltages \\
Fuzzy logic FLC \\
Sliding mode SM \\
Power quality
\end{tabular}

Power quality

\begin{abstract}
Sensitive loads are widely used in industrial, which is the main cause of sagswell and harmonics voltages problems that can affect the power quality. Among the devices that solve such power quality perturbations, the series active power Filter APFS is considered in this paper. Thus, a single phase APFS is developed through an analytic analysis, supported by an experimental validation, where we applied classical proportional integrator PI, fuzzy logic FLC and sliding mode SM controllers to improve the dynamic response of the APFS. In addition, a comparative study between these control strategies has made in order to mitigate voltage sag-swell and especially harmonics, where the SMC has showed more effective and robust results compared to PI and FLC and proved by the Total harmonic distortion THD ratio. Results of the proposed controllers are simulated in MATLAB simulink ${ }^{\circledR}$ and validated through experimental tests applied on our system prototype.
\end{abstract}

Copyright (C) 2019 Institute of Advanced Engineering and Science. All rights reserved.

\section{Corresponding Author:}

Abdallah Ben Abdelkader, Faculty of Electrical Engineering, University of Tahri Mohammed Bechar, Algeria

Email: Abdallahbenabdelkader@yahoo.fr

\section{INTRODUCTION}

Given the demand of improving the power quality especially in industry, where the critical equipment and sensitive loads are widely used and their power supply should not interrupted. Here, uninterrupted, clean and regulated power supply is required when feeding loads that have important tasks. On the other hand, most common voltage disturbances appear in alternative current appliances AC providing a reduction in voltage amplitude known as sag. Thus, sag and interruptions provide most of the industrial problems (90\%) that affect their supply quality [1]. Moreover, swell problem is also among disturbances that affect the power quality, which is defined by a rising in voltage amplitude above its nominal value [2]. In addition, harmonic distortion can provide huge problems in the whole of the power conversion chain such as heating the system components, mechanical oscillations, unpredictable behavior of protecting devices, and may cause damage $[3,4]$.

Due to these problems, it is necessary to approve protecting devices and effective solution to solve such disturbances. In this paper, we focus on serie active power filter (APFS) in order to mitigate sag-swell and harmonics [5-8] that affect our system. Thus, a serie compensator inserted between the source and the load called dynamic voltage restorer DVR is also implemented in this work to protect operating voltage of sensitive and critical appliances against sag problem especially [9-12]. APFS have the same topology as the active filter, with an excellent dynamic capability to restore the load voltage to i nominal value within a few milliseconds as well providing power disruption to the supplied loads. In other researches, the serie topology aims to compensate the sag with active power [13].In power quality domain, various paper has used classical 
and intelligent controllers in order to improve the stability, robustness and excellent dynamic response of the APFS as mentioned in [4, 15-18].The control strategies used in this paper such as PI, FLC and SMC presents robust and efficient results with different THD ratio, where SMC has provided the best ratio with 3\%. Models of the three controllers are developed mathematically as cited in various works such as [19-24], and adapted to our system topology.

The rest of the paper is organized as follows: section1 presents the APFS model with modeling of the power system, section 2 focuses on the control strategies with a comparative study between the used strategies and finally, this paper ends with a conclusion.

\section{DESCRIPTION OF THE SYSTEM}

\subsection{Series active power filter APFS}

In this paper, the studied system is composed mainly by three blocks, a programmable AC source to provide sag-swell and harmonics voltages scenarios, a sensitive load (medical equipment) and APFS. The APFS contains a single-phase PWM voltage source inverter in order to inject the compensating voltage by an injection transformer and an Lf, $\mathrm{Cf}$ second order filer to eliminate high frequency caused by inverter switching actions. This inverter is supplied by a DC source as shown in Figure 1.

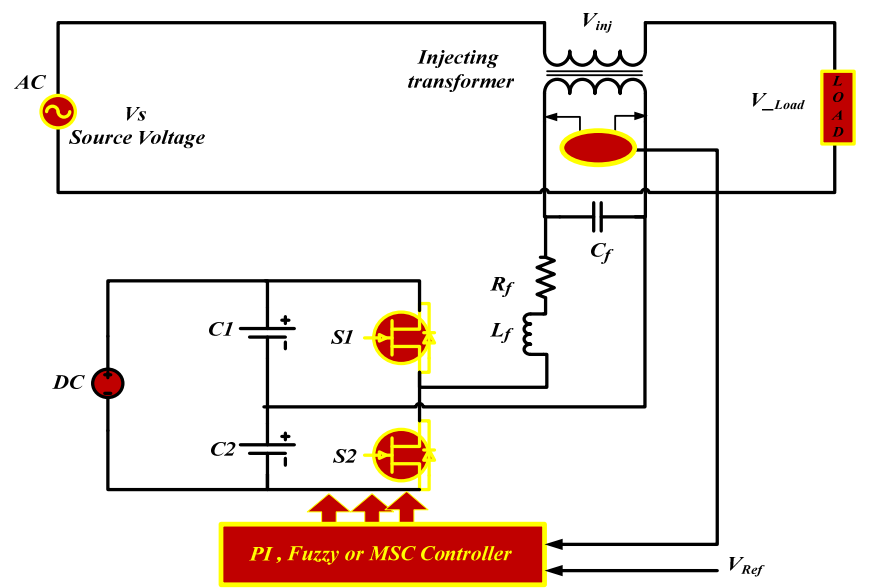

Figure 1. Single-phase series active power filter (ASF)

\subsection{Modeling of the APFS system}

This section deals with the mathematical modeling of the series active power filter APFS. The full structure of the APFS can be represented by a converter as shown in Figure 2, where Kirchhoff's voltage law is applied to the $\mathrm{AC}$ closed circuit to get the following mathematical expression [5]:

$$
\begin{aligned}
& m v_{0}=i_{L} R_{f}+L_{f} \frac{d i_{L}}{d t}+v_{i n j} \\
& v_{i n j}=i_{c} R_{c}+\frac{1}{C_{f}} \int\left(i_{c} d t\right)
\end{aligned}
$$

with:

$m$ : Control input to the series converter $i_{L}$ : Inductor current of the series converter $v_{i n j}$ : Output voltage of the series converter $v_{0}:$ de link voltage

$L_{f}$ : The inductance of the filter

$C_{f}$ : The capacitance of the filter

$R_{f}$ : Equivalent series resistance ESR of inductor

$R_{c}$ : The ESR of the capacitor 


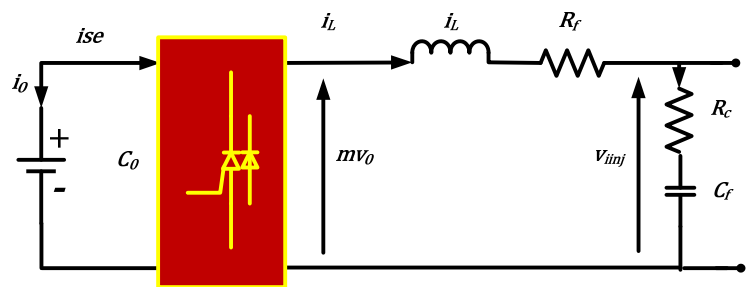

Figure 2. Equivalent circuit of series converter.

$$
\begin{aligned}
& \widehat{m}(s) V_{0}=\hat{\imath}_{L}(s)\left(R_{f}+s L_{f}\right)+\hat{\widehat{V}}_{i n j}(s) \\
& \hat{V}_{i n j}(s)=\hat{\imath}_{c}(s)\left(R_{c}+\frac{1}{s C_{f}}\right)
\end{aligned}
$$

\section{CONTROL STRATEGIES OF THE SYSTEM}

The control strategies used in this work are PI, FLC and SM controllers. Thus, a comparative study is made between the three methods in order to improve their performance and robustness in power quality. The 3 methods are described separately as follow:

\subsection{Classical proportional integrator PI controller}

The PI structure consists of a single outer voltage loop to regulate the injected voltage of the APFS. The output of this loop is the phase angle that is provided by the PWM signal generator. Thus, the PWM generates pulse signals to the gate of switching device IGBT [5]. The following transfer function defines the PI controller as:

$$
H_{i}(s)=K_{p}+\frac{K_{i}}{s}
$$

The PI controller cannot change abruptly in the error eps (Vref - Vrms). Therefore, PI controller can determines the instantaneous values of the error without considering their divergence and perturbations, which is defined by the derivate of the error and denoted $\Delta \mathrm{e}[5]$.

The transfer function of voltage-closed loop in series converter is defined in (6) using (4):

$$
G_{v s e}(s)=\frac{\hat{v}_{i n j}(s)}{\hat{\imath}_{c}(s)}=
$$

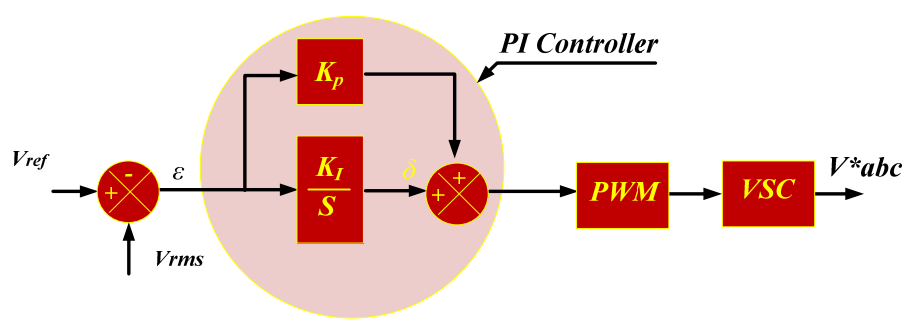

Figure 3. Controller with PWM and VSC

\subsection{Fuzzy logic controller FLC}

The second controller used in this paper is the FLC in order to improve the behavior of the APFS. The controller in based on Mamdani's system and its structure is shown in Figure 4.

Linguistic variables are the error $\mathrm{e}$ and its derivate $\Delta \mathrm{e}$, which are mapped from mathematical input values into fuzzy membership functions. After, executing all applicable rules in the rule base aims to compute the fuzzy output functions. Finally, by de-fuzzifying the fuzzy output functions, we get "crisp" output values.

A comparative study and experimental validation on single phase series active ... (Abdallah Ben Abdelkader) 


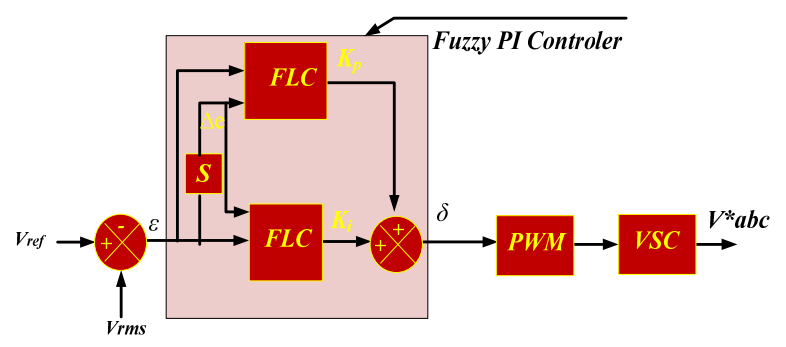

Figure 4. Fuzzy controller

These outputs are determined using the inference engine and the rule base (if-then rules) as follow: IF e AND $\triangle \mathrm{e}$, THEN $\mathrm{Kp}$ AND $\mathrm{Ki}$. The variation of $\mathrm{Kp}$ and $\mathrm{Ki}$ constants depend on (e and $\Delta \mathrm{e}$ ). The membership function curves of e, $\Delta \mathrm{e}, \mathrm{Kp}$ and $\mathrm{Ki}$ are shown in Figure 5 and 6 , where all memberships' functions have triangular shape [4].

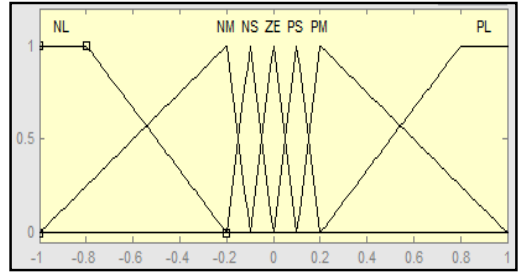

(a)

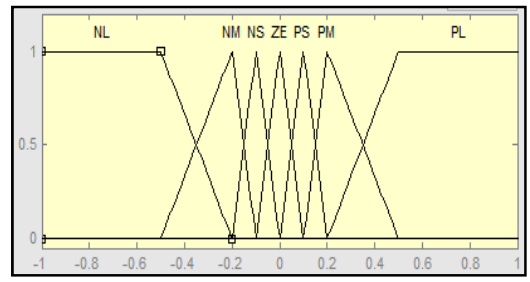

(b)

Figure 5. Membership function curves (a) error e, (b) Derrived of the error $\Delta \mathrm{e}$

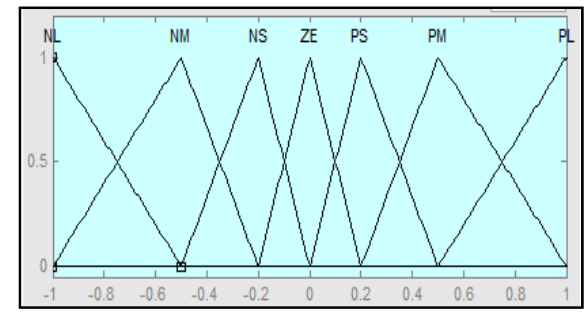

Figure 6. Membership function curves of both inputs $\mathrm{Kp}$ and $\mathrm{Ki}$

Thus, the fuzzy subset for e and $\Delta \mathrm{e}$ are (NL; NM, NS, ZE, PS, PM, PL). Table 1 presents the fuzzy logic control rules for the variables $\mathrm{Ki}$ and $\mathrm{Kp}$.

Table 1. Rule base for fuzzy controller

\begin{tabular}{cccccccc}
\hline $\begin{array}{c}\text { de(n) } \\
\text { e(n) }\end{array}$ & NB & NM & NS & ZE & PS & PM & PB \\
\hline NB & NB & NB & NB & NB & NM & NS & ZE \\
NM & NB & NB & NB & NM & NS & NZ & PS \\
NS & NB & NB & NM & NS & NZ & PS & PM \\
ZE & NB & NM & NS & ZE & PS & PM & PB \\
PS & NM & NS & ZE & PS & PM & PB & PB \\
PM & NS & ZE & PS & PM & PB & PB & PB \\
PB & ZE & PS & PM & PB & PB & PB & PB \\
\hline
\end{tabular}


In addition, a 3D curve of the relation between inputs and outputs of the FLC controller is also plotted and shown in Figure 7.

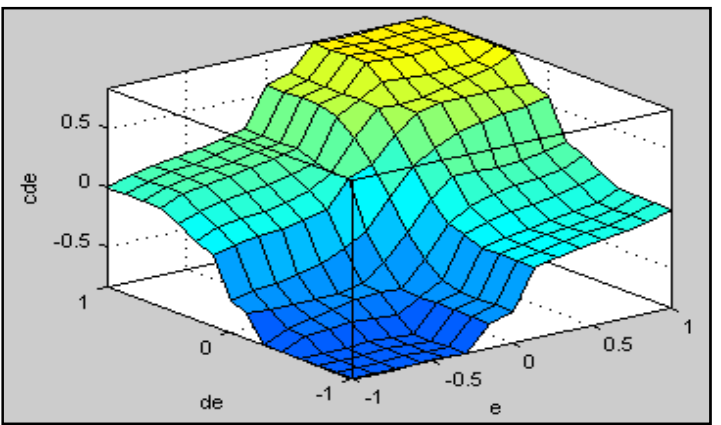

Figure 7. The relation surface between inputs and output of FLC

\subsection{Sliding mode controller SMC}

The last controller used is the SM controller described by the following state space model:

$$
\frac{d}{d t}\left[\begin{array}{l}
v_{c} \\
i_{f}
\end{array}\right]=\left[\begin{array}{cc}
0 & 1 / C_{f} \\
-1 / L_{f} & -R_{f} / L_{f}
\end{array}\right]\left[\begin{array}{l}
v_{c} \\
i_{f}
\end{array}\right]+\left[\begin{array}{cc}
-1 / C_{f} & 0 \\
0 & 1 / L_{f}
\end{array}\right]\left[\begin{array}{c}
i_{s} \\
\delta_{(t)} V_{d c}
\end{array}\right]
$$

where $i_{f}$ and $i_{s}$ are the filter inductor current and source current respectively.

Taking the injected voltage Vinj $=x_{1}$ and by derivate $x_{1}, \dot{x} 1=x 2$. Then, the description of the model become:

$$
\left.\begin{array}{l}
\dot{\mathrm{x}}_{1}=\mathrm{x}_{2} \\
\dot{\mathrm{x}}_{2}=-\frac{1}{\mathrm{~L}_{\mathrm{f}} \mathrm{C}_{\mathrm{f}}} \mathrm{x}_{1}-\frac{\mathrm{R}_{\mathrm{f}}}{\mathrm{L}_{\mathrm{f}} \mathrm{C}_{\mathrm{f}}} \mathrm{x}_{2}-\frac{\mathrm{R}_{\mathrm{f}}}{\mathrm{L}_{\mathrm{f}} \mathrm{C}_{\mathrm{f}}} \mathrm{i}_{\mathrm{s}}-\frac{1}{\mathrm{C}_{\mathrm{f}}} \frac{\mathrm{di}_{\mathrm{s}}}{\mathrm{dt}} \mathrm{u}+\frac{\mathrm{V}_{\mathrm{dc}}}{\mathrm{L}_{\mathrm{f}} \mathrm{C}_{\mathrm{f}}} \mathrm{u}
\end{array}\right\}
$$

first, we consider a general second order dynamic system as follow:

$$
\left.\begin{array}{l}
\dot{x}_{1}=x_{2}+\theta_{1} \varphi_{1}\left(x_{1}\right) \\
\dot{x}_{2}=\theta_{2} \varphi_{2}\left(x_{1}, x_{2}\right)+b\left(x_{1}+x_{2}\right) u
\end{array}\right\}
$$

Where, $\varphi_{i}(),. i=1,2$ are smooth functions with continuous finite time derivatives to exist and $b($.$) is invertible. The arguments of \varphi_{i}($.$) and b($.$) have been removed for simplicity in the analyses to$ follow. The parameters $\theta_{i}(),. i=1,2$ are known. Let the output of the system be $\operatorname{Vinj}=\mathrm{x}_{1 .} \cdot 1,2$. Define the error as[18].

The error dynamic is defined as follow:

$$
\left.\begin{array}{l}
z_{1}=V i n j_{\text {ref }}-V i n j=V i n j_{\text {ref }}-x_{1} \\
\dot{z}_{1}=V i n j_{\text {ref }}-x_{2}-\theta_{1} \varphi_{1}=z_{2} \\
\dot{z}_{2}=V \ddot{i n} J_{r e f}-\theta_{2} \varphi_{2}-b u-\theta_{1} \frac{\partial \varphi_{1}}{\partial x_{1}}+\left(x_{2}+\theta_{1} \varphi_{1}\right)
\end{array}\right\}
$$

The sliding surface with its derivation can be defined as follow:

$$
\begin{aligned}
& s=\lambda z_{1}+z_{2} \\
& \dot{s}=\lambda z_{2}+z_{2}
\end{aligned}
$$

After, using the following lyapunov function: $\mathrm{V}(\mathrm{s})=\frac{1}{2} \mathrm{~s}^{2}$, with its time derivative as follow:

$$
\dot{V}=s \dot{S}
$$


For stable operation, $\dot{\mathrm{V}}<0$, which results $\dot{\mathrm{S}}<0$ for $\mathrm{S}>0$ and $\dot{\mathrm{S}}>0$ for $\mathrm{S}<0$. Then, the control law can be represented as follow using eq13 and eq11:

$$
u=\frac{1}{b}\left[\lambda z_{2}+V \ddot{i n} J_{r e f}-\theta_{2} \varphi_{2}-\theta_{1} \frac{\partial \varphi_{1}}{\partial x_{1}}+\left(x_{2}+\theta_{1} \varphi_{1}\right)-\dot{s}\right]
$$

Figure 8 describes the feedback control diagram of the APFS. As shown, the Vloadref is the reference load voltage desired at the PCC. The error between Vloadref and Vload gives the reference injected voltage signal provided by the injection transformer. By comping the output of the low-pass filter with the injected reference voltage, we get the instantaneous error signal called $\mathrm{z} 1$. After, the error with its derivate (e, $\Delta \mathrm{e}$ ) are used by the sliding mode controller to generate the control law $\mathrm{u}$, which is converted to PWM signal of the switching device IGBT of the inverter [18].

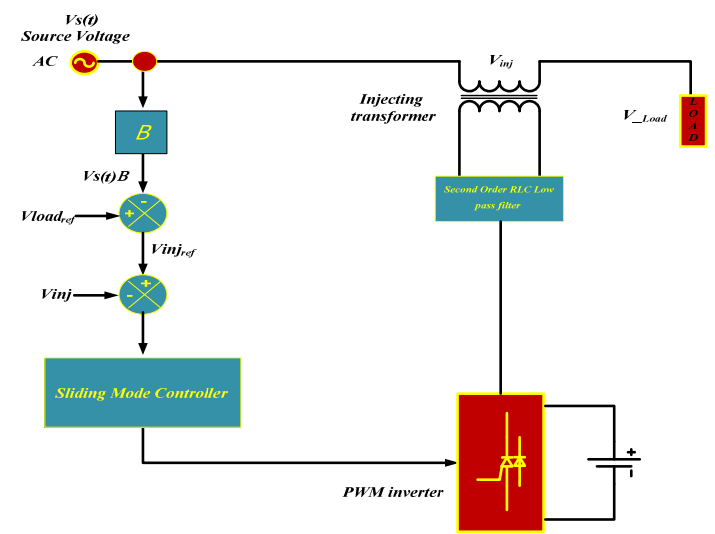

Figure 8. Feedback control change abruptly diagram of APFS

The error can be defined as follow

$$
\operatorname{Vinj}_{\text {ref }}(t)=\operatorname{Vload}_{\text {ref }}(t)-V s(t)
$$

Then, the error dynamic is derived using (2):

$$
\begin{aligned}
& z_{1}=V_{i n j_{\text {ref }}}-\text { Vinj }=\text { Vinj }_{\text {ref }}-x_{1} \\
& \dot{z}_{1}=\text { Vinj }_{\text {ref }}-\dot{x}_{1}=\text { Vinj }_{\text {ref }}-\dot{x}_{2}=\dot{z}_{2} \\
& \left.\dot{z}_{2}=V \text { inj }_{r e f}=V \ddot{i n} J_{r e f}+\frac{R_{f}}{L_{f}} V \text { inj }_{r e f}+\frac{1}{L_{f} C_{f}} V i n j_{r e f}-\frac{1}{L_{f} C_{f}} z_{1}-\frac{R_{f}}{L_{f}} z_{2}+\frac{R_{f}}{L_{f} C_{f}} i_{s}+\frac{1}{C_{f}} \frac{d i_{s}}{d t}-\frac{V d c}{L_{f} C_{f}} u\right\}
\end{aligned}
$$

The selected sliding surface was $\mathrm{s}=\mathrm{K}_{1} \mathrm{z}_{1}+\mathrm{K}_{2} \mathrm{z}_{2}$ along with the control law:

$$
s=f(s) * K \operatorname{sgn}(s)
$$

where

$$
\begin{aligned}
& f(s)=-\left[\frac{1}{q_{s s}}\right] \\
& q(s)=\left[\gamma+(1-\gamma) e^{-\alpha|s|} \csc \beta|s|\right]
\end{aligned}
$$

The next step is to obtain the sliding mode control law u using (14).

Finally, the control law can be derived using eq 14, 19 and 20 as follow:

$$
u=\frac{L_{f} C_{f}}{V d c}\left[\frac{k_{1}}{k_{2}} z_{2}+V \ddot{i n} J_{\text {ref }}+\frac{1}{L_{f} C_{f}} x_{1}+\frac{R_{f}}{L_{f}} x_{1}+\frac{R_{f}}{L_{f} C_{f}} i_{s}+\frac{1}{C_{f}} \frac{d i_{s}}{d t}\right]+\frac{1}{k_{2}}\left[\frac{k s g n(s)}{q(s)}\right]
$$




\section{RESULTS AND DISCUSSION}

In this section, we discuss the analytical and experimental results of the different control methods used in this study. First, we present simulation data, then we discuss the results. Thus, we present experimental results with a detailed discussion.

\subsection{Simulation results}

Simulation test has made in MATLAB Simulink ${ }^{\circledR}$ in order to improve the performance of the used control strategies such as PI, FLC and SMC. The simulation circuit is shown in Figure 9.



Figure 9: Simulation diagram of the system

Thus, simulation data are summarized in Table 2. The simulation results of the APFS are presented in order to improve its capability of ameliorating the power quality. The results are discussed separately, where a comparative analyses is made between the three controllers in the two case (sag-swell and harmonics).

Table 2. Electrical parameters

\begin{tabular}{cc}
\hline Parameters & Values \\
\hline Source voltage frequency f & $50 \mathrm{HZ}$ \\
Source voltage Vs & $5.7 \mathrm{Vrms}$ \\
Load resistance RL & $12.3 \Omega$ \\
Cf (LC filter inductance) & $1 \mathrm{nF}$ \\
Lf ( LC filter capacitance) & $9 \mathrm{mH}$ \\
Transformer & $12 \mathrm{~V} / 230 \mathrm{~V} / 1 \mathrm{KVA}$ \\
DC-bus capacitor, DC-bus & $2200 \mathrm{uF}-$ \\
reference voltage & $\mathrm{Vdc} *=35 \mathrm{~V}$ \\
Kp,Ki Simulation results & $\mathrm{Kp}=7,2-\mathrm{Ki}=33$ \\
Kp,Ki Experimental results & $\mathrm{Kp}=8,8-\mathrm{Ki}=4,24$ \\
Sliding mode controller & $k_{1}=250, k_{2}=0.023$ \\
parameters & $\alpha=57, \beta=400, \gamma$ \\
& $=0.001, k=0.01$ \\
\hline
\end{tabular}

\subsubsection{Case of the harmonics voltage :}

Figure 10, 11 and 12 present the voltage waveforms of PI, FLC and the SMC. The THD of the source voltage was $48.34 \%$. As shown, the APFS has compensated the voltage harmonics successfully. The three controllers have presented various excellent results, which is shown through ameliorating the voltage form and reducing the THD value. The THD has become $4.15 \%$ with PI controller, $3.88 \%$ with the FLC and $3.29 \%$ with the SMC. The following Figure 13, 14 and 15 show the spectral analysis for the three controllers. 


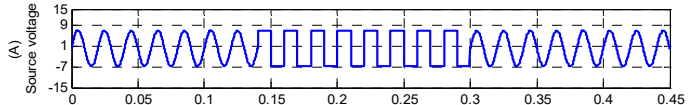

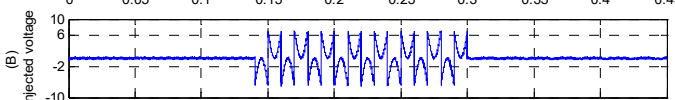

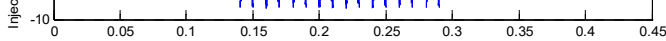



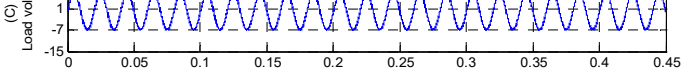

Time

Figure 10. Simulation voltage waveformes for PI Controller

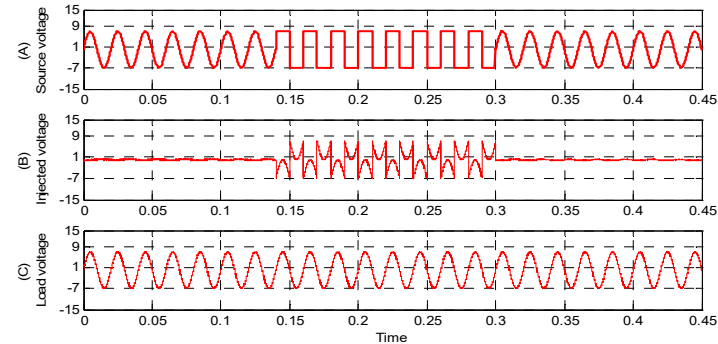

Figure 11. Simulation voltage waveformes for Fuzzy Controller



Figure 12: Simulation voltage waveformes for sliding mode Controller

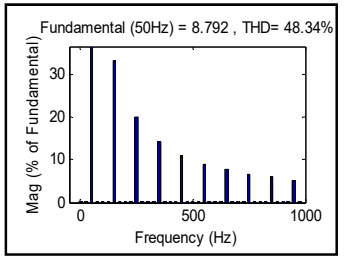

(a)



(b)

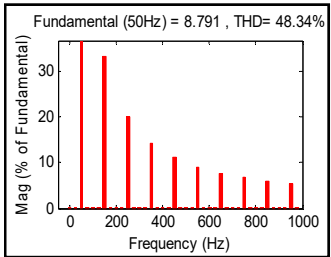

(a)

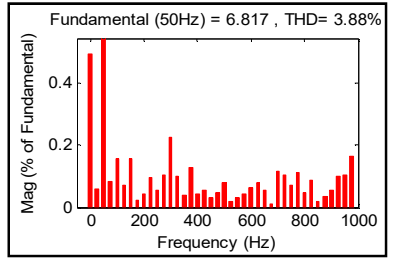

(b)

Figure 13. Spectral analysis for PI controller, (a) source voltage, (b) load voltage

Figure 14. Spectral analysis for fuzzy controller (a) source voltage, (b).load voltage

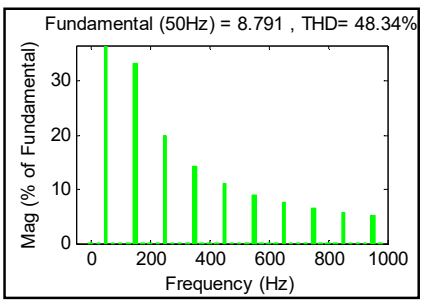

(a)



(b)

Figure 15. Spectral analysis for sliding mode controller (a) source voltage, (b) load voltage.

As a result, the sliding mode controller has presented the lowest THD value, which reflects the robustness and the efficiency of the control structure. 


\subsubsection{Case of the sag-swell voltage:}

In these cases of sag and swell voltage, we prove the ability of the APFS to compensate the unbalance voltage sags and swells. Figure 16, 18 and 20 shows the phase voltage source with sag of 50\%, which occurred during $[0.14 \mathrm{~s}-0.3 \mathrm{~s}]$. The three controllers has corrected the load voltage (Vlaod $\mathrm{RMS}=6.871 \mathrm{~V})$ with compensating the missed voltage $(50 \%$ in this case refer to $3.4355 \mathrm{~V})$.

The swell voltage phenomenon is shown in Figure 17, 19 and 21, where we used a 50\% as swell voltage during the same tame domain as mentioned in sag case. Thus, the three controllers has also corrected the swell voltage phenomenon by injecting a voltage in phase position in order to mitigate the over-voltage ratio $(50 \%$ in this case refer to $3.4355 \mathrm{~V})$.



Figure 16. Simulation voltage waveformes for PI Controller



Figure 19. Simulation voltage waveformes for fuzzy controller controller

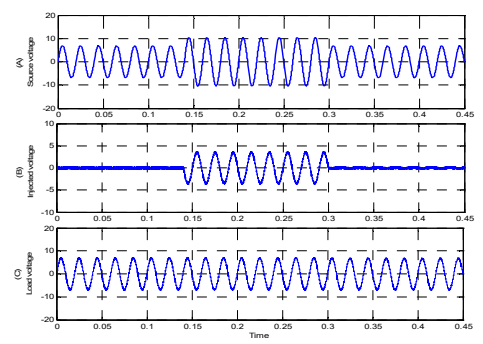

Figure 17. Simulation voltage waveformes for PI Controller

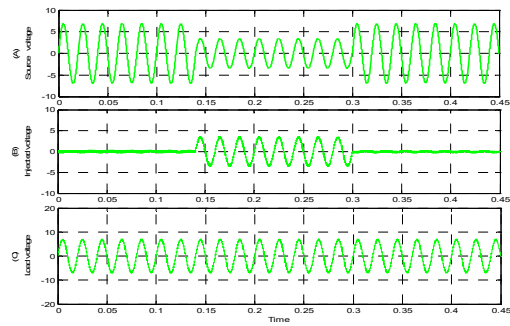

Figure 20. Simulation voltage waveformes for sliding mode controller

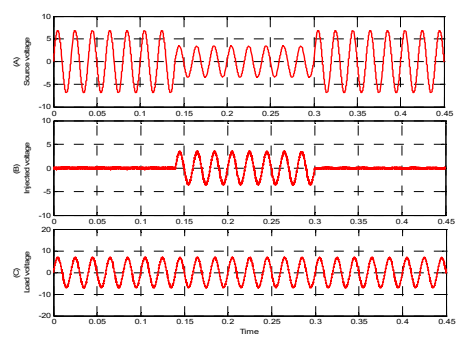

Figure 18. Simulation voltage waveformes for fuzzy controller

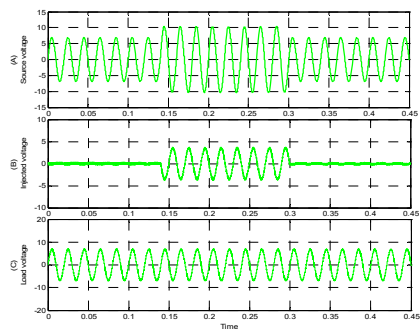

Figure 21. Simulation voltage waveformes for sliding mode controller

\subsection{Experimental results}

The experimental results to validate the simulation tests and improve the robustness of the used control methods. As in simulation, the experimental results are discussed separated in each phenomenon (sag-swell and harmonics voltage cases).

The experimental test has realized and elaborated in Smart Grid and Renewable Energies Laboratory (SGRE-Lab) in the University of TAHRI Mohamed-Béchar-Algeria. The experimental prototype includes a dSPACE card 1104 platform Texas Instrument with a TMS32F240 DSP connected with a PC (Pentium) in order to enable automatic implementation of the control methods directly from Matlab Simulink as illustrated in Figure 22.

Thus, the test bench consists of a voltage inverter, an inductor, an injection transformer, Hall current/ voltage sensors, linear load and a programmed source. 


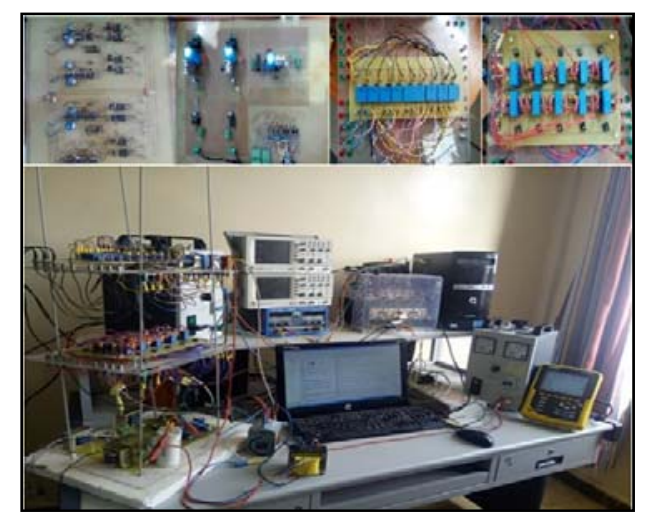

Figure 22: Experimental test banshee

\subsubsection{Case of the harmonics voltage}

The PWM switching gates was selected $15 \mathrm{KHz}$, which are generated from the dSPACE, card in real time experimental tests. Thus, a linear load was selected. As seen, the APFS has the ability to mitigate voltage harmonics provided by the grid and supplied to the connected load. The voltage harmonics are provided by the voltage inverter, which was connected in parallel with the source voltage. The harmonics was applied during $[5.6 \mathrm{~s}-6.3 \mathrm{~s}]$, where the initial THD before applying the control was about $46.4 \%$ as shown in Figure 24,26 and 28.
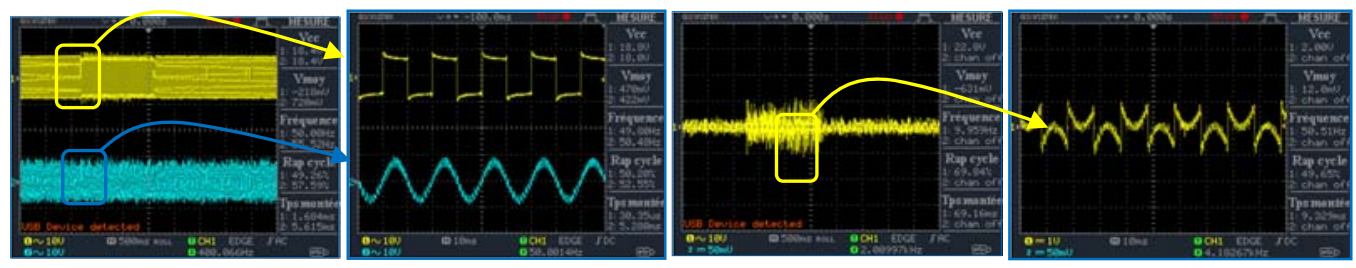

Figure 23. Experimental voltage waveformes for PI controller

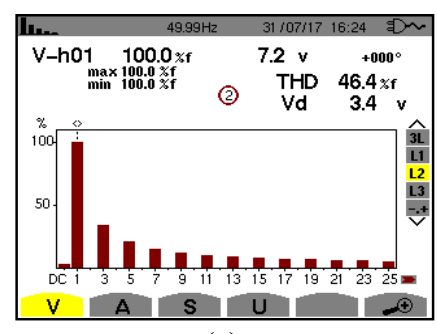

(a)

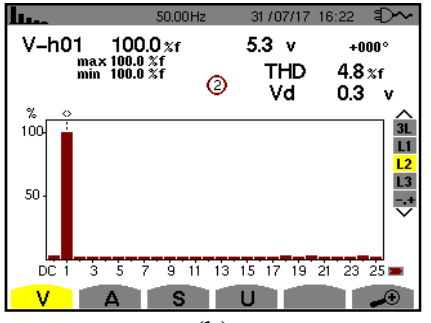

(b)

Figure 24. Spectral analysis of the source voltage (a) and load voltage (b) for PI controller
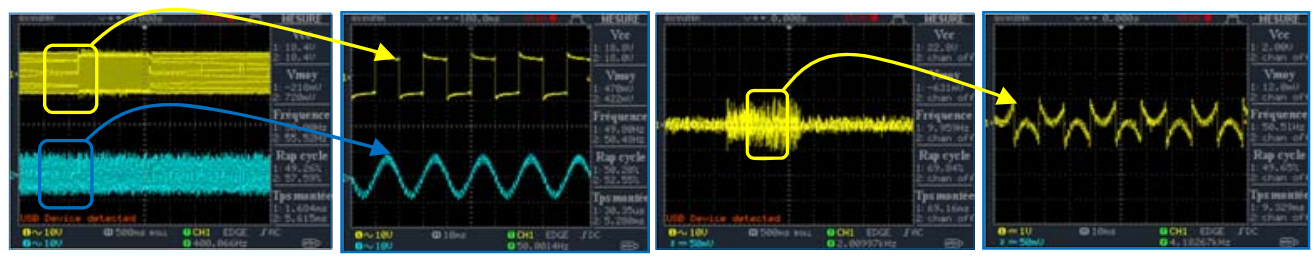

Figure 25. Experimental voltage waveformes for fuzzy controller 


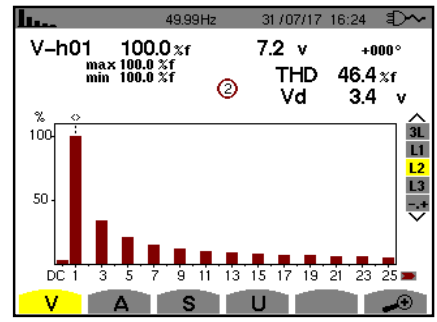

(a)



(b)

Figure 26. Spectral analysis of the source voltage (a) and load voltage (b) for fuzzy controller



Figure 27. Experimental voltage waveformes for sliding mode Controller

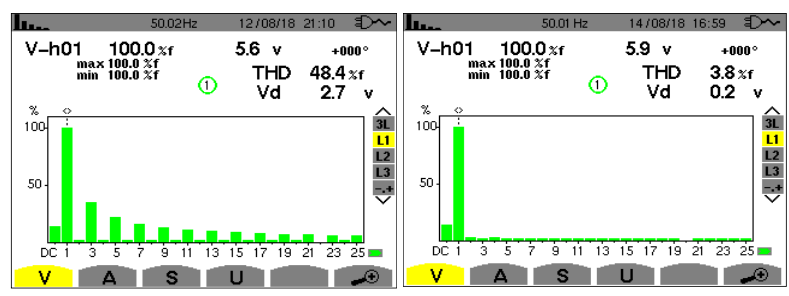

(a)

(b)

Figure 28. Spectral analysis of the source voltage (a) and load voltage (b) for sliding mode controller

\subsubsection{Case of the sag-swell voltage}

In addition, the reduction in the harmonics voltage compared by the initial THD value $(46.4 \%)$ is due to the compensation action of the APFS, where the experimental THD values measured using the Callister was very satisfying. The PI controller has provided a THD $=4.8 \%$, and better, the FLC has provided a $\mathrm{THD}=4.4 \%$, while the less $\mathrm{THD}$ value resulted by the $\mathrm{SMC}$ was about $\mathrm{THD}=3.8 \%$ as illustrated in Figure 24, 26 and 28. As a result, both of simulation and experimental THD values was within the norms of the IEEE 519 standard. In the other hand, sag and swell voltage of $50 \%$ were applied to the phase voltage source during [5.6s $-6.3 \mathrm{~s}]$ and $[0.7 \mathrm{~s}]$ respectively, where the APFS has compensated the missed and the over voltages provided by sag and swell phenomenon respectively Figure 27, 29 and 30. Table 3 present the comparison results between simulation and experimental tests.

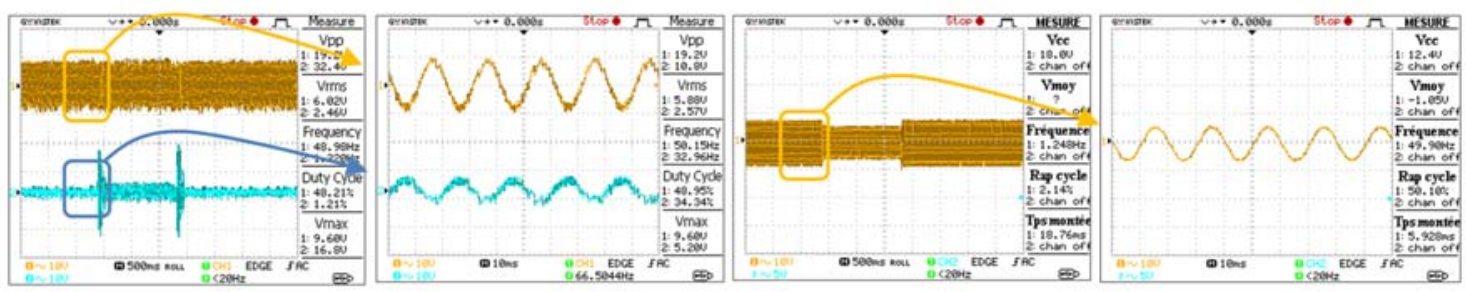

Figure 29. Experimental voltage waveformes for mode controller

A comparative study and experimental validation on single phase series active ... (Abdallah Ben Abdelkader) 



Figure 30. Experimental voltage waveformes for sliding mode controller

Table 3. comparison results between simulation and experimental tests.

\begin{tabular}{lllllll}
\hline Controllers & \multicolumn{2}{c}{ PI controller } & \multicolumn{2}{c}{ FLC controller } & \multicolumn{2}{c}{ SMC controller } \\
THD values & THD before & THD after & THD before & THD after & THD before & THD after \\
\hline $\begin{array}{l}\text { Simulation } \\
\text { results }\end{array}$ & $48.23 \%$ & $4.15 \%$ & $48.23 \%$ & $3.88 \%$ & $48.23 \%$ & $3.29 \%$ \\
$\begin{array}{l}\text { Experimental } \\
\text { results }\end{array}$ & $48.8 \%$ & $4.8 \%$ & $48.8 \%$ & 4.4 & $48.8 \%$ & $3.8 \%$ \\
\hline
\end{tabular}

\section{CONCLUSION}

Through this brief study, we have presented a topic about improving the quality of energy using the series active power filter APFS. The APFS has presented fast and specific reactions with the different voltage perturbance phenomenon such as sag-swell and harmonics. As previously explained, the used control method were PI, FLC and SMC, which have been chosen to show the reaction of APFS with perturbations using classical, intelligent and nonlinear control methods. In this study, we focused only on two parameters, which are the waveform of source and load voltages and the THD ratio. Thus, the controllers have presented excellent results in both simulation and experimental tests, with respecting to the norms of the IEEE 519 standard. Exactly, the three methods has compensating the sag and swell voltages by the filter, whit keeping a sinusoidal waveform of the load voltage despite the perturbance. In addition, among these controllers, the SMC has improved the lowest THD value compared with PI and FLC controllers due to the robustness of its control structure..

\section{ACKNOWLEDGEMENTS}

At the end of this work, I thank all doctor colleges and professors who participated in this work with their information's and who helped me as possible.I don't forget to thank Professor ABDELKHALEK Othmane, Smart Grid and Renewables Energies Laboratory (SGRE-Lab) for providing all necessary equipment and material and moral assistance

\section{REFERENCES}

[1] A. Prasai and D. M. Divan. "Zero-energy sag correctors-Optimizing dynamic voltage restorers for industrial applications". IEEE Transactions on Industry Applications, vol. 44, no. 6, pp. 1777-1784, 2008.

[2] H. Akagi, E. H. Watanabe and M. Aredes. "Instantaneous power theory and applications to power conditioning". John Wiley \& Sons, 2017.

[3] E. C. dos Santos, C. B. Jacobina, J. A. A. Dias and N. Rocha. "Single-phase to three-phase universal active power filter”. IEEE Transactions on Power Delivery, vol. 26, no. 3, pp. 1361-1371, 2011.

[4] A.ben abdelkader O. Abdelkhalek and A. Allali. "Experimental Validation of Single Phase Series Active Power Filter Using Fuzzy Control Technique". International Journal of Power Electronics and Drive Systems (IJPEDS), vol. 9, no. 2, pp. 591-601, 2018.

[5] M. S. I. S. A. Y. S. S. T. AMIT. "Design and control of single-phase dynamic voltage restorer". Indian Academy of Sciences Sadhana, vol. Vol. 42, No. 8, pp. pp. 1363-1375, 2017.

[6] R. Lawrence. "Power quality and electrical reliability: Where does the responsibility lie?". Energy Engineering, vol. 106, no. 6, pp. 23-33, 2009.

[7] H. Akagi and K. Isozaki. "A hybrid active filter for a three-phase 12-pulse diode rectifier used as the front end of a medium-voltage motor drive". IEEE transactions on power Electronics, vol. 27, no. 1, pp. 69-77, 2012.

[8] A. Chaoui, J. P. Gaubert, F. Krim and G. Champenois. "PI controlled three-phase shunt active power filter for power quality improvement". Electric Power Components and Systems, vol. 35, no. 12, pp. 1331-1344, 2007.

[9] M. H. Bollen and M. H. Bollen. "Understanding power quality problems: voltage sags and interruptions". IEEE press New York, 2000.

Int J Pow Elec \& Dri Syst, Vol. 10, No. 2, June 2019: $731-743$ 
[10] A. Sannino, M. G. Miller and M. H. Bollen. "Overview of voltage sag mitigation". Power Engineering Society Winter Meeting, 2000. IEEE, IEEE, pp. 2872-2878, 2000.

[11] D. J. Carnovale and T. J. Hronek. "Power quality solutions and energy savings—what is real?". Energy Engineering, vol. 106, no. 3, pp. 26-50, 2009.

[12] N. Athanasiadis. "Power quality solutions for voltage sags using dynamic voltage restorers". Electric Power Components and Systems, vol. 31, no. 2, pp. 159-170, 2003.

[13] J. G. Nielsen, M. Newman, H. Nielsen and F. Blaabjerg. "Control and testing of a dynamic voltage restorer (DVR) at medium voltage level”. IEEE Transactions on power electronics, vol. 19, no. 3, pp. 806-813, 2004.

[14] P. S. Babu and N. Kamaraj. "Performance investigation of dynamic voltage restorer using PI and fuzzy controller". Power Energy and Control (ICPEC), 2013 International Conference on, IEEE, pp. 467-472, 2013.

[15] F. B. Ajaei, S. Afsharnia, A. Kahrobaeian and S. Farhangi. "A fast and effective control scheme for the dynamic voltage restorer". IEEE transactions on power delivery, vol. 26, no. 4, pp. 2398-2406, 2011.

[16] F. Jowder. "Design and analysis of dynamic voltage restorer for deep voltage sag and harmonic compensation". IET generation, transmission \& distribution, vol. 3, no. 6, pp. 547-560, 2009.

[17] M. J. Newman, D. G. Holmes, J. G. Nielsen and F. Blaabjerg. "A dynamic voltage restorer (DVR) with selective harmonic compensation at medium voltage level". Industry Applications Conference, 2003. 38th IAS Annual Meeting. Conference Record of the, IEEE, pp. 1228-1235, 2003.

[18] A. Pandey, R. Agrawal, R. S. Mandloi and B. Sarkar. "Sliding Mode Control of Dynamic Voltage Restorer by Using a New Adaptive Reaching Law". Journal of The Institution of Engineers (India): Series B, vol. 98, no. 6, pp. 579$589,2017$.

[19] F. Mekri, M. Machmoum, B. Mazari and N. A. Ahmed. "Determination of voltage references for series active power filter based on a robust PLL system”. In Industrial Electronics, 2007. ISIE 2007. IEEE International Symposium on, IEEE, pp. 473-478, 2007.

[20] K. Sandhya, A. J. Laxmi and M. Soni. "Design of PI and fuzzy controllers for Dynamic Voltage Restorer (DVR)". AASRI Procedia, vol. 2, pp. 149-155, 2012.

[21] Y. Chang, L. Jinjun, W. Xiaoyu and W. Zhaoan. "A novel control of series active power filter without harmonics detection”. Power Electronics Specialists Conference, 2007. PESC 2007. IEEE, IEEE, pp. 1112-1115, 2007.

[22] A. Ramos, I. Nuez and V. Feliu. "Linearisation method and control for series active power filter by means of pulsewidth modulation". IEE Proceedings-Electric Power Applications, vol. 153, no. 3, pp. 337-342, 2006.

[23] F. B. Ajaei, S. Farhangi and R. Iravani. "Fault current interruption by the dynamic voltage restorer". IEEE transactions on power delivery, vol. 28, no. 2, pp. 903-910, 2013.

[24] D. M. Vilathgamuwa, A. R. Perera and S. S. Choi. "Voltage sag compensation with energy optimized dynamic voltage restorer". IEEE Transactions on Power Delivery, vol. 18, no. 3, pp. 928-936, $2003 .$. 